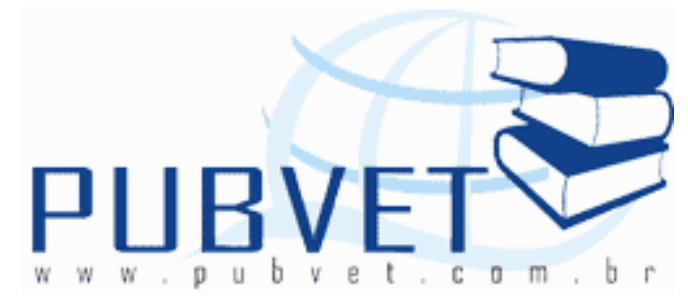

PUBVET, Publicações em Medicina Veterinária e Zootecnia.

\title{
Melhoramento genético de frangos de corte
}

Julyana Machado da Silva Martins ${ }^{(1)}$, Fernanda Heloisa Litz ${ }^{(2)}$, Henrique Castilhano $^{(3)}$,Danilo Fernandes Campos ${ }^{(4)}$, Rodrigo Zaiden Taveira ${ }^{(5)}$, Osvaldo José da Silveira Neto ${ }^{(5)}$

(1)(2) Pós-graduandas em Ciências Veterinárias - Universidade Federal de Uberlândia

(3) Zootecnista Autônomo

(4) Graduando em Medicina Veterinária - Universidade Federal de Uberlândia

(5) Docentes na Universidade Estadual de Goiás - São Luís de Montes Belos

\section{Resumo}

A avicultura industrial brasileira tem se expandindo a cada ano, devido aos avanços tecnológicos nas áreas de genética, nutrição e sanidade. No melhoramento genético de frangos de corte várias pesquisas são realizadas a fim de identificar linhagens com características superiores em relação a outras, selecionando, dessa forma, aves que apresentem melhor desempenho. Este intenso trabalho de seleção e melhoramento genético realizado nos últimos anos permitiu o amplo avanço da avicultura. A seleção é a estratégia de melhoramento mais praticada, que tem como objetivo o ganho genético sobre uma determinada característica ou em um conjunto de características de interesse. Em geral todas as companhias produtoras de linhagens comerciais fazem uso do principio da hibridação também conhecida como heterose. É de 
MARTINS, J.M.S. et al. Melhoramento genético de frangos de corte. PUBVET, Londrina, V. 6, N. 18, Ed. 205, Art. 1371, 2012.

extrema importância o conhecimento das características genéticas de desempenho e da relação destas para favorecer o estabelecimento mais preciso e adequado das estratégias utilizadas nos programas de seleção. Face ao exposto, objetivou-se relatar de maneira sucinta o histórico e o panorama do melhoramento genético no Brasil, as estratégias utilizadas no melhoramento de frangos de corte, as principais linhagens e a herança das principais características zootécnicas em frangos de corte.

Palavras-chave: Avicultura Industrial, Heterose, Seleção.

\begin{abstract}
Brazilian poultry industry has been expanding every year, due to technological advances in genetics, nutrition and health. In broiler chicken breeding several surveys are conducted to identify progeny with superior characteristics over other, this way selecting birds that shows better performance. This intense selection and genetic improvement work made in recent years has enabled a wide advancement of poultry industry. The selection is the most used breeding strategy, which aims to gain in a particular genetic trait or a set of characteristics of interest. In general, all companies producing commercial breeding use the principle of hybridization also known as heterosis. It is of extreme importance to study the characteristics of genetic performance and their relationship to favor the establishment of more accurate and appropriate strategies used in breeding programs. Given the above, the aim was to relate briefly the history and prospects of genetic improvement in Brazil, the strategies used in the breeding of broilers, the main lines and the inheritance of the main characteristics in broiler husbandry.
\end{abstract}

Keywords: Heterosis, Industrial Aviculture, Selection.

\title{
1 INTRODUÇÃO
}

A avicultura industrial brasileira tem se expandindo a cada ano, devido aos avanços tecnológicos nas áreas de genética, nutrição e sanidade, tendo 
MARTINS, J.M.S. et al. Melhoramento genético de frangos de corte. PUBVET, Londrina, V. 6, N. 18, Ed. 205, Art. 1371, 2012.

sido impulsionada pelo crescimento da demanda associada à mudança no padrão de consumo.

Desde o início da produção de frangos de corte no Brasil, a cadeia produtiva modernizou-se, devido à necessidade de redução de custos e aumento de produtividade, buscando com isso não perder competitividade em nível mundial. Como consequência, tem sido uma das mais organizadas do mundo, destacando-se das demais criações pelos resultados alcançados não só em produtividade e volume de abate, como também no desempenho econômico, onde tem contribuído de forma significativa para a economia do país (GIROTTO e AVILA, 2011).

O Brasil é o terceiro maior produtor mundial de frangos, com cerca de 12,230 milhões de toneladas produzidas no ano de 2010, representando um crescimento de $11,38 \%$ em relação a 2009 , quando foram produzidas 10,980 milhões de toneladas. Também no ano de 2010 o Brasil exportou cerca de 3,819 milhões de toneladas de carne de frango, permanecendo na posição, conquistada em 2004, de maior exportador mundial de carne de frango(UBABEF, 2011a). No primeiro trimestre de 2011 exportou 933 mil toneladas, representando um aumento de $10,1 \%$ em comparação com as 848 mil toneladas exportadas no mesmo período de 2010 (UBABEF, 2011b).Esses números confirmam o crescimento da avicultura no país, a sua importância social e econômica.

A competitividade e a evolução da indústria avícola brasileira têm estimulado a constante busca da melhoria do material genético dos frangos de corte. Pesquisas avaliando esses produtos são realizadas a fim de identificar linhagens com características superiores em relação a outras, selecionando, dessa forma, aves que apresentem melhor desempenho (STRINGHINI et al., 2003).

O melhoramento genético avícola proporcionou grandes avanços no crescimento e desenvolvimento do frango de corte. Atualmente, existem no mercado várias linhagens disponíveis para atender diferentes finalidades. As curvas de crescimento possuem comportamentos diferentes conforme as 
MARTINS, J.M.S. et al. Melhoramento genético de frangos de corte. PUBVET, Londrina, V. 6, N. 18, Ed. 205, Art. 1371, 2012.

linhagens e sexo (MARCATO et al., 2010), além do mercado que se deseja atingir.

Face ao exposto, objetivou-se relatar de maneira sucinta o histórico e o panorama do melhoramento genético no Brasil, as estratégias utilizadas no melhoramento de frangos de corte, as principais linhagens e a herança das principais características zootécnicas em frangos de corte.

\section{REVISÃO DA LITERATURA}

\subsection{Histórico do Melhoramento Genético Avícola Nacional}

O imenso desenvolvimento da avicultura brasileira, nas últimas décadas, ocorreu em função da importação de material genético de alta qualidade, introduzido no país a partir 1962 (BOARETTO, 2009).

Mesmo que a importação de material genético tenha sido a propulsora para o desenvolvimento da avicultura, não justificava tornar o país sempre dependente desse material. Então em 1965, o governo federal publicou um decreto, que proibia a importação de pintos comerciais e matrizes, permitindo a entrada apenas de avós. O decreto determinava ainda que a partir de 1967, a importação de aves ficaria condicionada à execução de trabalhos de melhoramento genético de aves no Brasil. Porém foi cumprido apenas no tocante à proibição da importação de pintos comerciais e matrizes (MENDES e SALDANHA, 2004).

Dessa forma, alguns órgãos de pesquisa iniciaram projetos de genética e melhoramento de aves com o objetivo de produzir linhagens brasileiras, utilizando recursos liberados pelo governo federal. Os principais projetos implantados foram o do Instituto de Genética anexo à Escola Superior de Agricultura Luiz de Queiroz (ESALQ), da Universidade Federal de Viçosa (UFV), do Instituto de Zootecnia (IZ) de Nova Odessa e da Universidade Federal de Pelotas (LANA, 2000). 
MARTINS, J.M.S. et al. Melhoramento genético de frangos de corte. PUBVET, Londrina, V. 6, N. 18, Ed. 205, Art. 1371, 2012.

Porém, nenhum dos programas conseguiu produzir uma linhagem realmente eficiente, com condições de competir com o material genético importado (MENDES e SALDANHA, 2004).

A exceção foi a Granja Guanabara, que após trabalhar durante alguns anos com uma empresa canadense, iniciou o seu próprio programa de melhoramento genético, e em 1972, lançou no mercado três linhagens, sendo uma para corte e duas para postura. Como as linhagens tinham uma parte muito pequena do mercado brasileiro, a empresa acabou encerrando suas atividades, sendo o material genético remanescente adquirido pelo Ministério da Agricultura e transferido para o Centro Nacional de Pesquisas de Suínos e Aves da Embrapa, localizado em Concórdia, Santa Catarina (SILVA, 2009).

A partir do ano de 2001, a Embrapa reduziu o programa, passando a priorizar a produção de aves do tipo caipira ou colonial, utilizando o material genético existente (MORO et al., 2005).

Conforme MENDES e SALDANHA (2004), a estrutura da avicultura nacional está dividida em algumas atividades: um número reduzido de granjas importadoras chamadas "avozeiros"; filiais de empresas estrangeiras; e empresas nacionais trabalhando sob o regime de contrato de representação do produto. Essas granjas produzem as matrizes que são criadas nas granjas "matrizeiras" que, por sua vez, vendem pintos de um dia para as granjas de engorda de frangos destinados ao abate.

Ainda hoje são importados todos os materiais genéticospuros,entretanto, algumas empresas já fazem, no país, diretamente ou porintermédio de parcerias, desenvolvimento genético a partir de linhagens puras. Como o caso da empresa Agroceres Ross Melhoramento Genético de Aves S.A., composta pela Agroceres e a Aviagen (JESUS JUNIOR et al., 2007), e da Coob-Vantress que inaugurou em 2001, uma granja de bisavós da linhagem Cobb, localizada em Nova Granada, São Paulo (SANTINI, 2006). 
MARTINS, J.M.S. et al. Melhoramento genético de frangos de corte. PUBVET, Londrina, V. 6, N. 18, Ed. 205, Art. 1371, 2012.

\subsection{Panorama do Melhoramento Genético Avícola no Brasil}

A produção de aves no Brasil é crescente, havendo, portanto, incremento por demanda de material genético de alta qualidade (SILVA, 2009).

Apesar de existirem alguns programas brasileiros de produção de material genético, a avicultura brasileira caracteriza-se por dependência da tecnologia genética estrangeira quase que total (VAYEGO, 2007; SILVA, 2009).Dessa forma, o objetivo dos programas de melhoramento é a independência de material genético estrangeiro, já que as economias com as importações são relativamente grandes, além de evitar doenças e outros problemas relacionados com a importação (LANA, 2000).

Dentro desse contexto vale ressaltar que apesar da necessidade de importação de material genético ainda ser um fator limitante para a avicultura brasileira, ela também é um incentivo para que institutos de pesquisa e iniciativa privada desenvolvam parcerias com o intuito de tornar o país autosuficiente na obtenção de materiais genéticos para garantir a produção avícola (SILVA, 2006b).

Atualmente as Universidades Federal de Viçosa, Federal de Santa Maria, Federal de Pelotas, a ESALQ e a Embrapa, desenvolvem programas de melhoramento genético de aves no Brasil (SILVA, 2009).

A partir da multiplicação do material genético importado, institutos de pesquisas e iniciativa privada possuem a missão de produzir aves adaptadas às necessidades climáticas e de manejo, e que possuam altos índices produtivos para atender, de maneira adequada, às demandas, interna e externa, do mercado consumidor (BRUM, 2005).

De acordo com FIGUEIREDO et al. (2000), as principais vantagens de se utilizar linhagens nacionais de frangos são estratégicas e incluem: redução no risco de introdução de doenças exóticas; desenvolvimento de linhagens próprias, com material genético competitivo, utilizando ferramentas e metodologia de última geração, como biologia molecular e avaliação de genótipos pelo uso de modelo animal, podendo servir como exemplo para 
MARTINS, J.M.S. et al. Melhoramento genético de frangos de corte. PUBVET, Londrina, V. 6, N. 18, Ed. 205, Art. 1371, 2012.

outras espécies de ciclo biológico mais longo; produto de barganha na negociação com outros países; independência das restrições impostas por outros países; e economias de divisas na importação de material genético. Além de vantagens ligadas a interação genótipo-ambiente, pois as linhas puras são selecionadas no local onde se destinam a produzir, reduzindo os inconvenientes da interação genótipo-ambiente nas características de desempenho.

\subsection{Melhoramento Genético de Frangos de Corte}

O melhoramento genético de linhagens avícolas tem contribuído para a crescente eficiência da avicultura brasileira (SILVA et al., 2007). É uma das áreas de produção animal que tem por objetivo obter uma população com genótipo superior para combinação de características de importância econômica(VAYEGO, 2007).

O melhoramento inicia-se com a escolha dos melhores animais para a reprodução, métodos de cruzamentos e seleção. Assim, a obtenção de resultados satisfatórios em programas de melhoramento depende de diversos fatores, como: objetivos e estrutura do programa, coleta de dados, importância econômica das características, parâmetros genéticos, tamanho da população, intensidade de seleção, métodos de seleção e progresso genético esperado (LANA, 2000).

A definição dos objetivos do programa de melhoramento é o primeiro e talvez o mais importante passo a ser dado. A escolha errada das características a serem melhoradas pode ser equivalente ou até pior do que não promover o melhoramento de nenhuma característica. Se muitos reprodutores forem selecionados por razões irrelevantes aos objetivos do programa, então o grupo de animais escolhido provavelmente não será tão bom quanto o esperado em relação às características de interesse. É importante, no processo de seleção, que os critérios sejam bem definidos e 
MARTINS, J.M.S. et al. Melhoramento genético de frangos de corte. PUBVET, Londrina, V. 6, N. 18, Ed. 205, Art. 1371, 2012.

que a seleção seja eficiente em relação aos objetivos do programa (KINGHORN et al., 2006).

\subsubsection{Seleção}

O intenso trabalho de seleção e melhoramento genético realizado nos últimos anos permitiu o amplo avanço da avicultura (GROSSO, 2010). A seleção é a estratégia de melhoramento mais praticada, tendo como efeito básico a alteração das frequências alélicas nos locos que controlam a característica sob seleção, conduzindo à alteração na média genotípica da população na direção desejada pelo melhorista. Tem como objetivo o ganho genético sobre uma determinada característica ou em um conjunto de características de interesse econômico (VAYEGO, 2007). Entretanto, é necessário que o objetivo e o critério de seleção sejam bem definidos, para o programa de melhoramento genético animal funcionar (VIANA et al., 2000).

O critério de seleção representa o conjunto de informações a respeito de uma característica ou conjunto de características em que a seleção se baseia, visando avaliar e ordenar os candidatos à seleção para a característica alvo do melhoramento. Contudo, enquanto uma correta definição do objetivo da seleção depende da avaliação do produto de interesse e de informações econômicas desse produto, para a definição do critério de seleção são necessárias informações a respeito dos parâmetros genéticos, como herdabilidades e correlações genéticas, e fenotípicas associados às características envolvidas no melhoramento (VAYEGO, 2007).

De acordo com SOUZA e MICHELAN FILHO (2004), num processo de seleção em uma população o primeiro passo é selecionar os melhores indivíduos (aumentando a frequência dos genes desejáveis). Posteriormente obtém o diferencial de seleção $(\Delta S)$, através da diferença entre a média dos indivíduos selecionados e a média da população.

As características de importância econômica no melhoramento animal são, em geral, resultantes da ação combinada de muitos pares de genes e 
MARTINS, J.M.S. et al. Melhoramento genético de frangos de corte. PUBVET, Londrina, V. 6, N. 18, Ed. 205, Art. 1371, 2012.

influenciadas, em parte, pelo meio ambiente. Portanto, ao se estudar uma característica, é necessário considerar que, além dos efeitos genéticos, existe a ação do meio ambiente na sua expressão fenotípica (LANA, 2000). Ou seja, o fenótipo ( $F$ ) é influenciado por vários pares de genes de efeitos aditivos e sua expressão depende do valor genotípico $(G)$, do meio ambiente $(A)$, e das correlações entre os dois (GXA) (CARNEIRO JúNIOR et al., 2004).

$\mathrm{Na}$ genética avícola para se prever o ganho genético esperado é preciso estimar a herdabilidade $\left(\mathrm{h}^{2}\right)$. As variações causadas pelo ambiente podem ser grandes e economicamente importantes, mas não podem ser transmitidas à próxima geração. A variação genética é a que realmente importa, pois é ela que possibilita os ganhos genéticos, que podem ser acumulativos de geração para geração. O ganho genético pode ser definido como (SOUZA e MICHELAN FILHO, 2004):

$$
\begin{aligned}
& \Delta \mathrm{G}=\Delta \mathrm{S} \times \mathrm{h}^{2}, \text { sendo: } \\
& \Delta \mathrm{G}=\text { Ganho genético; } \\
& \Delta \mathrm{S}=\text { Diferencial de seleção; } \\
& \mathrm{h}^{2}=\text { Herdabilidade. }
\end{aligned}
$$

Os mesmos autores ainda ressalvam que o ganho genético em uma característica é inversamente proporcional ao número de características sob seleção. Ou seja, quanto maior o número de características do critério de seleção menor o ganho em cada uma.

O estudo de medidas repetidas é de suma importância nas avaliações genéticas, pois diversas características deinteresse na produção animal são avaliadas repetidas vezes ao longo da vida do animal (LÔBO et al., 2010).

\subsubsection{Formação das linhagens híbridas}

Os programas de melhoramento genético de aves são embasados na variabilidade genética dos indivíduos, quepode ser alterada por meio da introdução de novos genótipos no plantel. A hibridação é usada com frequência na condução dos programas de melhoramento genético de aves, cujo sucesso 
MARTINS, J.M.S. et al. Melhoramento genético de frangos de corte. PUBVET, Londrina, V. 6, N. 18, Ed. 205, Art. 1371, 2012.

depende da divergência genética dos progenitores. Assim, indivíduos mais produtivos poderão ser gerados com o uso de progenitores que apresentem altos índices de produtividade e grande diversidade genética (PIRES et al., 2002).

SOUZA e MICHELAN FILHO (2004), citam que existem quatro razões para o frango ser um híbrido: obtenção de heterose, complementaridade de características produtivas, especificidade e segurança do patrimônio genético.

A heterose é definida como sendo a superioridade nos parâmetros produtivos da progênie em relação às raças e/ou linhagens puras que thes deram origem. A complementaridade pode ser entendida quando uma linhagem completa a outra em um dado parâmetro. Exemplo a linha macho é eficiente em ganho de peso, eficiência alimentar e conformação, estas características complementam a linhagem de fêmeas, que são deficientes nessas características, tornando o frango de corte ou produto final do melhoramento mais eficiente zootecnicamente (BRUM, 2005).

Já a especificidade é entendida como sendo o ganho genético em uma característica, é inversamente proporcional ao número de características de seleção. Isto é, quanto maior o número de características em seleção, menor o ganho em cada uma. Assim, o uso dos conceitos de complementaridade e especificidade atenua o efeito indesejável do número excessivo de características do critério de seleção, sendo de vital importância nos programas de melhoramento genético para frangos (SOUZA e MICHELAN FILHO, 2004).

A segurança do patrimônio genético, quer dizer, que apenas os animais híbridos são comercializados, evitando assim a reconstituição das linhagens puras e garantindo o investimento realizado pela companhia de melhoramento genético (SOUZA e MICHELAN FILHO, 2004).

Em geral todas as companhias produtoras de linhagens comerciais fazem uso do princípio da hibridação também conhecida como heterose. Dois amplos métodos são usados: desenvolvimento de linhagens não-consaguíneas, que são usadas para produzir as linhagens comerciais através de cruzamento; ou o 
MARTINS, J.M.S. et al. Melhoramento genético de frangos de corte. PUBVET, Londrina, V. 6, N. 18, Ed. 205, Art. 1371, 2012.

desenvolvimento de linhas consaguíneas através de intensa consaguinidade, levando finalmente ao cruzamento dessas linhagens, que constituirão os híbridos. Uma diferenciação importante entre os dois métodos é que uma seleção intrapopulação é usada no desenvolvimento das linhagens consaguíneas, ou seja, a seleção é feita entre indivíduos ou famílias dentro de uma mesma linhagem. A quantidade de consaguinidade existente, neste caso, é consequência simples do tamanho da população (LANA, 2000).

As companhias que utilizam o desenvolvimento de linhagens nãoconsaguíneas fazem-no na base do desempenho de cada linhagem, ou ainda, na base de como indivíduos de uma linhagem combinam bem com os indivíduos de outra linhagem. Em particular, as seleções são baseadas no desempenho individual de cada linhagem pura ou no desempenho do cruzamento das duas linhagens. Esta última é chamada de seleção recorrente recíproca. Neste caso, a linhagem $A$ é melhorada pela seleção dos machos $A$ cruzados com fêmeas de $B$ e, reciprocamente, os machos de $B$ são selecionados na base de como eles cruzam com as fêmeas de $A$. O método é utilizado para que se tire vantagem máxima dos efeitos de interações gênicas que porventura ocorram entre as duas linhagens A e B (LANA, 2000).

Assim SOUZA e MICHELAN FILHO (2004), registram que a formação das linhagens comerciais de frangos de corte existentes, é um híbrido, oriundo do cruzamento de três ou quatro linhagens puras. Em geral duas linhagens de fêmeas que dão origem à fêmea matriz e uma ou duas linhagens de macho que dão origem ao macho matriz.

$\mathrm{Na}$ seleção das linhas paternas enfatiza-se as características de peso corporal, conversão alimentar, viabilidade geral e específica, rendimento de carcaça, rendimento de peito, gordura na carcaça, empenamento e ausência de defeitos. Nas linhas maternas, são enfatizadas as características de viabilidade geral e específica, fertilidade, eclodibilidade, produção de ovos incubáveis, empenamento e ausência de defeitos (VAYEGO, 2007). Essa divisão em linhas deve-se à correlação genética negativa existente entre as características de produção e reprodutivas (SILVA, 2006a). 
MARTINS, J.M.S. et al. Melhoramento genético de frangos de corte. PUBVET, Londrina, V. 6, N. 18, Ed. 205, Art. 1371, 2012.

As raças que contribuíram para a formação do frango de corte moderno são: pelo lado paterno, a raça combatente inglesa Cornish, variedade alvirrubra de penas brancas e vermelhas que através de retrocruzamento chegaram à linhagem branca dominante; pelo lado materno, a variedade White Plymouth Rock, branca recessiva, oriunda da raça Plymouth Roch Barrada. O frango apresenta a plumagem branca devido à dominância da linha macho (CAMPOS, 2000).

\subsubsection{Genética molecular}

Os avanços da biologia molecular trouxeram consigo um novo e amplo campo de pesquisas direcionadas ao melhoramento e conservação de recursos genéticos (LÔBO et al., 2010).

O termo genoma é utilizado para designar toda a informação genética de um organismo. O estudo do genoma visa o conhecimento amplo da estrutura e função dos genes (LEDUR et al., 2003).

Atualmente, o conhecimento dos genomas é a principal fronteira da genética avícola. Com os sequenciamentos, foi possível determinar as funções específicas de boa parte dos genes que formam cada um dos genomas. Em um programa de melhoramento genético avícola, isto passa a ser fundamental, para se melhorar o processo de seleção (LEDUR et al., 2011)

Todas as informações geradas a partir de estudos genômicos serão essenciais para incorporação em programas que visem melhorar a produção e qualidade do produto final. As informações provenientes da genética molecular podem ser usadas para implementar estratégias de melhoramento através da seleção assistida por marcadores, que por sua vez pode ser utilizada em conjunto com a seleção fenotípica, na introgressão de determinada característica de uma população para outra, mantendo as características desejáveis da população receptora e também na predição do desempenho e heterose da progênie resultante do cruzamento (LEDUR et al., 2003). 
MARTINS, J.M.S. et al. Melhoramento genético de frangos de corte. PUBVET, Londrina, V. 6, N. 18, Ed. 205, Art. 1371, 2012.

Conforme LEDUR e SCHMIDT (2000), a genética molecular oferece grandes oportunidades para o melhoramento de aves, principalmente para características de baixa herdabilidade, como as reprodutivas; que se expressam somente em um sexo, como produção de ovos; relacionadas à resistência genética a doenças; que exigem o sacrifício do animal para serem obtidas, como as relacionadas a rendimento e qualidade da carne; relacionadas a problemas metabólicos (ascite e morte súbita); e relacionadas a comportamento animal.

LEDUR et al. (2011), relatam que em frango de corte a seleção genômica poderá melhorar a reposta à seleção principalmente pela maior acurácia na estimativa dos valores genéticos e em menor grau pela redução do intervalo de gerações, que já é pequeno.

\subsection{Principais Linhagens de Frango de Corte}

FERNANDES et al. (2002), afirmam que o uso de linhas genéticas de diferentes fontes comerciais em programas de frangos de corte permite produzir gerações mais bem adaptadas a diversas realidades e otimizar os potenciais de desempenho. As linhagens comercialmente disponíveis apresentam variabilidade entre as características de valor econômico delas dependentes. Diferenças importantes existem no desempenho, rendimentos de carcaça e de cortes.

Em geral, as companhias de melhoramento genético possuem diferentes linhagens com intenção de adequá-las a diferentes segmentos de mercado e ou regiões (ARAÚJO et al., 2002; SOUZA e MICHELAN FILHO, 2004). As principais linhagens de frangos de corte existentes no Brasil são: Ross, Cobb, Arbor Acres, Avian, Hubbard, Isa, Ag Ross, HiSex, Hibro, Chester e Embrapa (JESUS JUNIOR et al., 2007). 
MARTINS, J.M.S. et al. Melhoramento genético de frangos de corte. PUBVET, Londrina, V. 6, N. 18, Ed. 205, Art. 1371, 2012.

\subsection{Herança das Principais Características Zootécnicas no Frango de Corte}

O conhecimento das características zootécnicas em frangos de corte e de suas correlações pode favorecer o estabelecimento mais preciso e adequado das estratégias utilizadas nos programas de seleção (MADEIRA et al., 2010).

Conforme VIANA et al. (2000), programas de melhoramento genético necessitam de acompanhamento das características de importância econômica. A partir destes estudos é que os critérios de seleção são estabelecidos para garantir a renovação dos plantéis com animais de potencial genético superior geração após geração.

\subsubsection{Velocidade de crescimento}

Trata-se de uma característica fundamental no melhoramento do frango de corte (SOUZA, 2002). Conceitua-se velocidade de crescimento como sendo o peso vivo alcançado à idade de mercado (CAMPOS, 2000).

O grande progresso na criação do frango foi à redução da idade de abate (SOUZA e MICHELAN FILHO, 2004). A idade de abate das aves diminuiu de 105 dias, em1930, para 49 dias em 1970, chegando, em 2005, a 42 dias (JESUS JUNIOR et al., 2007).

É uma característica de alta estimativa de herdabilidade $(0,60)$ em qualquer idade considerada, entretanto, está relacionada com o desempenho reprodutivo, pois, quanto mais pesado for o plantel de reprodução, mais comuns são os problemas com produção de ovos e fertilidade (CAMPOS, 2000). E com a deposição excessiva de gordura, problemas de fraqueza de pernas e ascite, que é uma demonstração de que o sistema circulatório da ave nem sempre suporta a grande massa corporal que possui (VAYEGO, 2007). 
MARTINS, J.M.S. et al. Melhoramento genético de frangos de corte. PUBVET, Londrina, V. 6, N. 18, Ed. 205, Art. 1371, 2012.

Dessa forma conforme CAMPOS (2000), as correlações entre peso e idade são altas constituindo fatores importantes para a avaliação da taxa de crescimento.

\subsubsection{Conversão alimentar}

O melhoramento genético em aves permitiu a criação de linhagens altamente eficientes na conversão alimentarde rações em peso (VAYEGO, 2007). A conversão alimentar representa o consumo de ração por quilo de frango produzido (MORAES, 2000). Muitas vezes ocorre engano entre conversão alimentar e eficiência alimentar, pois a eficiência alimentar se baseia na eficiência com que o alimento é convertido em tecido corporal e geralmente medida em porcentagem (PEREIRA, 2004).

A relação entre eficiência alimentar e ganho em peso vivo é de importância, tanto econômica como biológica. Até recentemente, o melhoramento genético da eficiência de utilização dos alimentos nas aves de corte tem sido alcançado quase que inteiramente como resposta a período de crescimento. Em geral, aves de crescimento mais rápido, entre ou dentro de linhagens, são mais eficientes em converter alimentos em peso corporal do que aquelas de crescimento mais lento. As correlações genéticas entre ganho em peso e conversão alimentar, medidas em vários intervalos, variam de 0,25 a 0,70 (PEREIRA, 2004).

De acordo com SOUZA e MICHELAN FILHO (2004), a estimativa de herdabilidade para conversão alimentar é de 0,25 a 0,50. Trata-se de uma característica de herdabilidade variando de baixa a média, devido principalmente às implicações de meio (CAMPOS, 2000).

A conversão alimentar pode ser medida a um peso constante ou a intervalos de idades. No primeiro caso, há favorecimento às vezes de maior velocidade de crescimento e redução acentuada das exigências de mantença. No segundo caso, ocorre penalização das aves que apresentam maior 
MARTINS, J.M.S. et al. Melhoramento genético de frangos de corte. PUBVET, Londrina, V. 6, N. 18, Ed. 205, Art. 1371, 2012.

velocidade de crescimento, visto que, sendo mais pesadas, provocam custo de manutenção mais alto (PEREIRA, 2004).

\subsubsection{Taxa de sobrevivência}

A estimativa de herdabilidade desta característica é baixa, variando de 0,01 a 0,05. O grande problema está associado com as doenças metabólicas que vêm ocorrendo com as linhagens modernas, como a síndrome de morte súbita e a ascite, as quais podem ser controladas pelo manejo das aves (CAMPOS, 2000).

Desde o alojamento dos pintos o número de aves mortas e refugadas é anotado diariamente, o qual é usado para o cálculo da viabilidade. Esta é calculada pela diferença de aves alojadas e o número de aves retiradas para o abate. O resultado é sempre representado em porcentagem (MENDES e PATRÍCIO, 2004)

A resistência geral a doenças é uma meta muito procurada no melhoramento genético de frangos de corte, mas sua seleção é difícil no ambiente da maioria dos lotes de avós, porque tendem a estar livres das doenças mais comuns. Uma exceção a algumas destas restrições foi à seleção para resistência à doença de Marek. Antes da introdução de vacinas que fornecem proteção, várias empresas adotaram estratégias de exposição controlada em locais remotos para identificar linhagens e famílias resistentes. Geralmente, pode ser encontrada resistência genética a doenças específicas, mas permanece a questão se a seleção para esta resistência tem de fato valor econômico (VAYEGO, 2007).

\section{6 Índice de Eficiência Produtiva}

A maioria das empresas utiliza a comparação deste índice para mensurar seu resultado. Por ser o resultado de uma fórmula que engloba os mais 
MARTINS, J.M.S. et al. Melhoramento genético de frangos de corte. PUBVET, Londrina, V. 6, N. 18, Ed. 205, Art. 1371, 2012.

importantes índices zootécnicos a sua aceitação é muito grande (MORAES, 2000).

Este índice varia em função da Viabilidade (VB), do Ganho Médio de Peso Diário (GMD), e da Conversão Alimentar (CA), na retirada do lote. Estes índices são calculados da seguinte forma, onde no numerador encontram-se agrupados todos os fatores que devem ser maximizados e, no denominador, o que deve ser reduzido (MENDES e PATRÍCIO, 2004):

IEP = Ganho Médio de Peso Diário (Kg) x Viabilidade (\%)x 100, sendo:

\section{Conversão alimentar}

GMD = Peso Final - Peso Inicial / Idade em dias;

$\mathrm{CA}=$ Consumo de ração do lote/ Ganho de peso do lote;

VB $=100 \%$ - Mortalidade (\%).

\section{CONSIDERAÇÕES FINAIS}

O crescimento observado na produção de frangos de corte nos últimos anos tem impulsionado a busca por produtos genéticos cada vez melhores, tornando de suma importância a avaliação constante de índices de desempenho zootécnico de frangos de corte, para nortear os programas de seleção e melhoramento genético das linhagens.

O melhoramento genético avícola é dinâmico, onde estudos comparativos entre linhagens não representam tendências permanentes para as características avaliadas, pois o frango de corte evolui continuamente e seguirá ganhando peso, melhorando a conversão alimentar e aumentando a taxa de sobrevivência ao longo das gerações.

Continuarão sendo no futuro, extremamente proveitosos, como foram no passado, investimentos destinados às pesquisas em melhoramento genético de aves, para tornar o país independente de material genético externo, e consequentemente, maximizar a cadeia produtiva de aves. 
MARTINS, J.M.S. et al. Melhoramento genético de frangos de corte. PUBVET, Londrina, V. 6, N. 18, Ed. 205, Art. 1371, 2012.

\section{REFERÊNCIAS BIBLIOGRÁFICAS}

ARAÚJO, L. F. et al. Diferentes Perfis de Aminoácidos para Frangos de Corte no Período de 43 a 56 Dias de Idade. Revista Brasileira de Zootecnia, v.31, n.1, p.387-393, 2002.

BOARETTO, T. N. Melhoramento Genético em Frangos de Corte. Revista

Formação Informação Zootecnia, v. 1, n.1, 2009.

BRUM, O. B. Efeito do Cruzamento entre Diferentes Genótipos para Uso em Sistemas Alternativos de Frango de Corte. 2005. 47f. Dissertação (Mestrado em Zootecnia) - Centro de Ciências Rurais. Santa Maria: Universidade Federal de Santa Catarina, 2005.

CAMPOS, E. J. Avicultura: razões, fatos e divergências. Belo Horizonte: FEP-MVZ Editora, 2000. $311 \mathrm{p}$.

CARNEIRO JÚNIOR, J.et al. Avaliação de Métodos de Estimação de Componentes de Variância Utilizando Dados Simulados. Revista Brasileira de Zootecnia, v 33, n 2, p. 328-336, 2004.

FERNANDES L. M.; VIEIRA S. L.; BAPTISTA C. B. Desenvolvimento de Órgãos da Digestão e Rendimento de Carcaça de Frangos de Corte de Diversas Origens Genéticas Criados com Bebedouros Pendular e Nipple. Revista Brasileira de Ciência Avícola, v.4, n.1, p. 73-84, 2002.

FIGUEIREDO, E. A. P. et al.O programa de melhoramento genético de aves da EMBRAPA. In. SIMPÓSIO NACIONAL DE MELHORAMENTO ANIMAL, 3., 2000, Belo Horizonte. Anais... Belo Horizonte, 2000. p. $58-62$.

GIROTTO, A. F.; AVILA, V. S. de. Sistemas de Produção de Frangos de Corte. On-line. Disponível em: www.sistemasdeproducao.cnptia.embrapa.br. Acessado em: 23 de Abril de 2011.

GROSSO, J. L. Estimação dos Valores Genéticos e Econômicos para as Características sob Seleção. Produção Animal Avicultura, v.4, n.40, p.37, 2010.

JESUS JUNIOR, C. A Cadeia da Carne de Frango: tensões, desafios e oportunidades. BNDES Setorial, n.26, p. 191-232, 2007.

KINGHORN, B.; WERF, J.; RYAN, M. Melhoramento Animal: uso de novas tecnologias. Piracicaba: FEALQ, 2006. p.18.

LANA, G. R. Q.. Avicultura. Recife: Livraria e Editora Rural Ltda, 2000. 268 p.

LEDUR, M. C.; BERTANI, G. R.; NONES, K. Genômica nos Programas de Melhoramento Genético Avícola. In: CONFERÊNCIA APINCO 2003 DE CIÊNCIA E TECNOLOGIAS AVÍCOLAS, 2003, Campinas. Anais...Campinas: FACTA, 2003. p. 87-105.

LEDUR, M. C.; PEIXOTO, J. O.; SCHMIDT, G. S. Novos Rumos da Genética no Desenvolvimento Avícola. Avicultura Industrial, v.102, n.01, p. 12- 16, 2011.

LEDUR, M. C.; SCHMIDT, G. S. Genética Molecular: aplicação de tecnologias moleculares no melhoramento genético de aves. Avicultura Industrial, v.90, n.02, ed. 1075, p.13-19, 2000. 
LÔBO, R. B. Progresso científico em melhoramento animal no Brasil na primeira décadado século XXI. Revista Brasileira de Zootecnia, v.39, p.223-235, 2010.

MADEIRA, L. A.et al. Avaliação do desempenho e do rendimento de carcaça de quatro linhagens de frangos de corte em dois sistemas de criação. Revista Brasileira de Zootecnia, v. 39, n. 10, p.2214-2221, 2010.

MARCATO, S. M. et al. Crescimento e Deposição de Nutrientes nos Órgãos de Frangos de Corte de Duas Linhagens Comerciais. Revista Brasileira de Zootecnia, v. 39, n.5, p. 1082-1091, 2010.

MENDES, A. A.; PATRÍCIO, I. S. Controles, registros e avaliação do desempenho de frangos de corte. In: MENDES, A. A.; NAAS, I. A.; MACARI, M. Produção de Frangos de Corte.

Campinas: FACTA, 2004. p. 323-335.

MENDES, A. A.; SALDANHA, É. S. P. B. A cadeia produtiva da carne de aves no Brasil. In: MENDES, A. A.; NAAS, I. A.; MACARI, M. Produção de Frangos de Corte. Campinas: FACTA, 2004. p. $1-22$.

MORAES, L. N. P. Atualização das Técnicas de Avaliação do Desempenho em Frangos de Corte. In: IV SIMPÓSIO GOIANO DE AVICULTURA, 2000, Goiânia, Anais...Goiânica: UP GRAFF, 2000. p.91-101.

MORO, D. N. et al. Desempenho Produtivo de quatro Linhagens de Frangos de Corte. Ciência Rural, v.35, n.2, p. 446-449, 2005.

PEREIRA, J. C. C. Melhoramento Genético aplicado à produção animal. 4 ed. Belo Horizonte: FEPMVZ, 2004.

PIRES, A. V. et al. Estudo da Divergência Genética entre Seis Linhas de Aves Legorne Utilizando Técnicas de Análise Multivariada. Arquivo Brasileiro de Medicina Veterinária e Zootecnia, v.54, n.3, p.314-319, 2002.

SANTINI, G. A. Dinâmica tecnológica da cadeia de frango de corte no Brasil. Análise dos segmentos de insumo e processamento. 2006. 269f. Tese (Doutorado em Engenharia de Produção) - Centro de Ciências Exatas e Tecnologia. São Carlos: Universidade Federal de São Carlos, 2006.

SILVA, D. O. S. Programa de Biosseguridade em Matrizes de Aves de Corte na Embrapa Suínos e Aves. 2006.61f. Monografia (Graduação em Zootecnia) - Instituto de Ciências Agrárias, Mineiros: Faculdade Integrada de Mineiros, 2006a.

SILVA, M. A. N. Interação Genótipo-Ambiente e Análise da Variabilidade no Melhoramento Genético de Linhagens de Avós de Frango de Corte. 2006. 82f. Tese (Doutorado em Agronomia) - Escola Superior de Agricultura Luiz de Queiroz, Piracicaba, Universidade de São Paulo, 2006b.

SILVA, M. A. N. et al. Fatores de Estresse Associados à Criação de Linhagens de Avós de Frangos de Corte. Revista Brasileira de Zootecnia, v.36, n.3, p.652-659, 2007.

SILVA, Martinho de Almeida. Evolução do Melhoramento Genético de Aves no Brasil. Revista Ceres, v.56, n. 4, p.437-445, 2009.

SOUZA, Eduardo Mendonça. Manejo de Matrizes: índices para medir a eficiência da produção de frangos de corte e reprodutoras. In: CONFERÊNCIA 
APINCO, 1002, 2002. Campinas. Anais... Campinas, FACTA, 2002, p. 151-164.

SOUZA, E. M.; MICHELAN FILHO, T. Genética avícola. In: MENDES, A. A.; NAAS, I. A.; MACARI, M. Produção de Frangos de Corte. Campinas: FACTA, 2004. p. 23-35.

STRINGHINI, J. H. et al. Avaliação do Desempenho e Rendimento de Carcaça de Quatro Linhagens de Frangos de Corte Criadas em Goiás. Revista Brasileira de Zootecnia, v. 32, n. 1 , p. 183-190, 2003.

UBABEF.Balanço Positivo. Avicultura Industrial, v.102, n.01, $2011 \mathrm{a}$.

UBABEF. Exportação de Frango sobe 10,1\% no primeiro trimestre.Avicultura Industrial, v.102, n.04, 2011b.

VAYEGO, S. A. Uso de Modelos Mistos na Avaliação Genética de Linhagens de Matrizes de Frango de Corte. 2007. 104f. Tese (Doutorado em Genética) - Setor de Ciências Biológicas.Curitiba: Universidade Federal do Paraná, 2007.

VIANA, C. F. A. et al. Influência de Grupos Genéticos e de Níveis de Energia sobre Características de Carcaça de Frangos de Corte, Revista Brasileira de Zootecnia, v.29, n.4, p.1074-1081, 2000. 